\title{
Editorial
}

\section{Men and the modern workplace}

\author{
Paula McGee RN RNT PhD MA BA Cert Ed \\ Editor, Diversity and Equality in Health and Care; Emerita Professor of Nursing, Faculty of Health, Education and Life Sciences, \\ Birmingham City University, Birmingham, UK
}

\section{Mark RD Johnson PhD MA Dip HE (Warwick)}

Editor, Diversity and Equality in Health and Care; Emeritus Professor of Diversity in Health and Social Care, Mary Seacole Research Centre, De Montfort University, Leicester, UK

Regular readers of this journal will know that we take a very broad view of diversity and equality issues: we are interested in gender, learning disability, living with long-term conditions such as poor mental health, race, ethnicity and inequalities in care. However, a recent leader in The Economist (Berkeley 2015) suggests that there is yet another kid on the block and a highly neglected one at that: working class men. The reactions have been, predictably, both vitriolic and patronising, for example, blaming women for working outside the home and blaming the American people for their failure to elect Senator George Wallace as President in 1968. At first glance it is difficult to see what the problem is. Men, especially white men, occupy the majority of positions of privilege throughout the world. Most political leaders are male: at the beginning of this year there were only ten female heads of state and fourteen governments led by women (UN Women http://www.unwomen.org). Men also dominate business: of the top 500 US companies listed by Fortune magazine, only 25 have female CEOs (Gallagher 2015). Only $20 \%$ of FTSE 100 companies have female CEOs (Groom 2015). Men also dominate all the major world religions as well as the sciences, legal systems and the arts. In every society patriarchy still flourishes and is still considered by many to be normal. It is "so universal, it cannot be the product of some vicious circle that was kick-started by a chance occurrence. ....It is far more likely that even though the precise definition of 'man' and 'woman' varies between cultures, there is some universal biological reason why almost all cultures valued manhood over womanhood. We do not know what this reason is" (Hariri 2011:153-4).

However, what we do know is that the last hundred years have brought immense changes as far as notions of manhood and womanhood are concerned. Women have benefited enormously from these changes. Access to education on a par with that previously only given to boys, equality before the law, political rights, employment opportunities and better economic prospects are now the norm in both developed and many developing countries. Women have forged ahead in many fields, often helped by the possession of social skills that facilitate interpersonal interaction and cooperative working. In evolutionary terms this has all happened very quickly. Within living memory are a series of firsts: Ivy Williams, the first woman called to the bar in England, 1922; Sarla Thakral the first woman pilot in India, 1937; Qiu Qianfang, the first woman train driver in Taiwan, 2012; Frances O'Grady, the first woman to lead the Trades Union Congress in Britain, 2012; Louise Richardson, the first woman vice-chancellor of Oxford University and Libby Lane the first female bishop in the Church of England. These firsts also reflect a period of huge technological change that has removed the need for many trades and occupations in manufacturing and other fields. This journal, for example, is written and published using computers; the centuries-old trade of compositor is no longer required. Steel, an essential product for so many modern day items, is still manufactured in blast furnaces but these are now controlled by computers; the many years of training required to manage open hearth furnaces has, in most places, been consigned to the past (http://www.steelconstruction.info/ Steel_manufacture).

Herein lies some of the problem. Many working class men who might, in the past, have been employed in manufacturing in skilled or unskilled jobs, now find themselves without jobs. Less educated and maybe less adaptable, they may have fewer prospects than their female counterparts. Poverty, boredom, frustration, depression and lack of opportunities can make it difficult to sustain long term relationships and family life particularly when benefit systems discourage cohabitation (Berkeley 2015). It is small wonder that, for some, crime presents a possible escape route. In the UK alone the prison population is predominantly male: 81,751 compared with 3,918 women (The Howard League for Penal Reform 2015) and data from other countries, such as the US, reveal similar pictures. Finding employment after prison is even harder, particularly if there was no job and only unsettled accommodation beforehand (Brunton-Smith and Hopkins 2014).

Thus whilst men cluster at the top of society, they also gather at the bottom. Dismissing them all as feckless scroungers and layabouts who can't be bothered to work does not help and neither does ignoring the situation. Large numbers of men with nothing to do or not enough to do and with no prospect of any improvement in their situation is a ticking bomb; men's frustration, anger and rage against social exclusion is something that should concern every society because it represents a route to total destruction. Technological changes may have improved life for many people but they have done so at a cost. Societies across the world have to consider how best to channel the energies and abilities of working class men and provide the encouragement, education and role models they need to establish pathways into modern workforces with a sense of pride in their work, and address this new area of inequality of wellbeing. We look forward to papers that address this neglected aspect of diversity.

\section{In this issue}

We begin this issue with another under-addressed topic. There is a worldwide market in skin whitening products worth an estimated 10 billion USD. African countries, the Indian subcontinent and Japan are major areas for sales. The products are aimed principally at women with black or dark coloured skin, acne scars, uneven skin colouring or who simply have freckles. However products are starting to emerge for men. 
Skin bleaching goes beyond the usual practices associated with personal grooming. Skin bleaching products contain mercury and other harmful substances that are used to reduce the production of the melanin which helps to colour the skin. In addition to the large manufacturers are local producers whose products may be cheaper but contain unspecified quantities of toxic substances. There are even websites that give instructions about making skin bleaching products using items to be found in most kitchen cupboards. As Ahmed and Saltus (2015) point out , the absorption of toxic substances causes mercury poisoning and damage to vital organs. Changes in the skin itself reduce protection against the harmful effects of UV light and may lead to cancer. The US Food and Drug Administration has warned against the use of products containing mercury (http://www.fda. gov/forconsumers/consumerupdates/ucm294849.htm). Ivory Coast banned skin bleaching products in May 2015 (Buchanan 2015). Doctors in other countries such as Senegal have expressed concern about the practice of skin bleaching. Nevertheless, large numbers of people continue to try to change their skin colour and seem willing to risk damaging their bodies in order to achieve the desired outcome. At the root of skin bleaching practices lie the social pressures piled on individuals, particularly young women, to conform to ideal images of how they should look. Inherent in these pressures is the devaluation of black skin colour and 'the current mass-marketing of contemporary images of white beauty' by well-known cosmetic firms and endorsed by celebrities. In many developing countries, the legacy of privilege associated with colonisation is a particularly powerful incentive (Hunter 2011:143). In this context pale white skin is not only valued for its appearance but, more importantly, what it confers: status, beauty and opportunity. Thus 'white or light skin is a form of "racial capital" gaining its status from existing racial hierarchies. Racial capital is a resource drawn from the body that can be related to skin tone, facial features, body shape, ... Light skin tone can be transformed into social capital (social networks), symbolic capital (esteem or status), or even economic capital (high-paying job or promotion)' Hunter 2011:145). Ahmed and Saltus' paper contributes to understanding of this symbolic capital. The young women in their study engage in skin bleaching to make themselves more attractive to potential husbands but in doing so maybe they increase their chances of finding higher status men with more resources and thus the possibility of better lives.

Women's health is also the subject of our next paper. Cervical cancer is one of the most common cancers affecting women but it is both preventable and. if detected early enough, treatable. It is women in poor countries who are most at risk because they do not have sufficient access to vaccination or to the regular screening that is essential to early detection of the disease. Döbrössy and colleagues, in our first paper from Hungary, highlight the inequalities in cervical screening services in Europe and reveal the disparity between the wealthy western nations and those that have recently joined the EU. Richer countries have the resources to organise population-based screening but in poorer parts of Europe, cervical screening is still opportunistic, meaning that it is the well off, better educated women who are most likely to benefit. Added to the inequalities is lack of education. There are still women who do not take up screening when it is offered, perhaps because they not understand why it is necessary, or because they fear the results. Education and the provision of women-centred services are essential in combating a disease which kills large numbers of women every year.

Our third paper presents a novel methodological approach. Darlington and colleagues have examined the data on inequalities in the health of minority ethnic groups in England. They have examined data from the annual Health Survey for England over several years to demonstrate changing patterns of ill health between and among different ethnic groups. This paper is a welcome addition to the literature on this complex topic and provides rare quantitative support to the debate.

Our final research paper concerns enabling members of minority ethnic groups to cope with long term illness. The use of IPA illustrates the difficulties in educating ethnically and religiously mixed groups about health-related issues. Hipwell and colleagues demonstrate that language is only one factor to consider, although it is very important, and remind us that there can be more variation between members of the same group, in this case Punjabi Sikhs, than between one ethnic group and another (Helman 2007). Issues of caste and social class must also be addressed. However, calls for separate education provision based on religion and culture would be very hard to support in a society as diverse as the UK. Nevertheless, there is some thought provoking material here which practitioners will find useful.

Finally, we present our three usual features. Our CPD paper this time takes up the issue of cervical cancer from Döbrössy and colleagues, and expands on the strengths and limitations of current preventative measures and approaches to screening. In the Practitioner's Blog, Mary Dawood presents an important issue that practitioners are likely to encounter with increasing frequency: dementia among members of minority ethnic groups. She rightly points out that many older minority ethnic adults are unable to communicate in English, the dominant language in her London hospital. There may be many reasons for this; some arrived in old age to be cared for by adult children and have not needed to learn English, others came to the UK many years ago in search of work and better prospects. They did not intend to stay so long, there was always the dream of going home but now they find that they are old and the home they left no longer exists (Anwar 1979). One element of dementia is the loss of acquired language skills. Whatever the reason, there is now a sizeable population of minority ethnic older adults, with varying levels of support and possibly limited English and they need care. Finally, in our Knowledgeshare section Nicky Hudson presents the usual roundup of pointers to useful information which we hope readers will find helpful.

\section{REFERENCES}

Anwar, M. (1979) The Myth of Return. Pakistanis in Britain. London, Heinemann.

Berkeley J (2015) The weaker sex. Blue-collar men in rich countries are in trouble. They must learn to adapt. The Economist May 30.

Brunton-Smith I, Hopkins K (2014) The impact of experience in prison on the employment status of longer-sentenced prisoners after release. Results from the Surveying Prisoner 
Crime Reduction (SPCR) longitudinal cohort study of prisoners. London, Ministry of Justice

Gallagher L (2015) 2015 predictions: 7 more women CEOs.... and the end of selfies? Fortune, January 8, http://fortune. com/2015/01/08/2015-predictions-fortune-500-cities/

Groom B (2014) Proportion of women on FTSE 100 boards tops $20 \%$. The Financial Times January 17,

Hariri Y (2011) Sapiens. A brief history of humankind. London, Harvill Secker

Helman, C. (2007) Culture, health and Illness, $5^{\text {th }}$ edn. London, Hodder Arnold

Hunter, M. (2011) Buying Racial Capital: Skin-Bleaching and Cosmetic Surgery in a Globalized World. The Journal of Pan African Studies, 4 (4):142-64

The Howard League for Penal Reform (2015 Weekly Prison Watch. Latest prison population figures. Week ending Friday 29 May 2015 http://www.howardleague.org/weekly-prisonwatch/ accessed 31.5.15 